\title{
Correction to: Recognition of evolving medial patellofemoral anatomy provides insight for reconstruction
}

\author{
Miho J. Tanaka ${ }^{1}$. Jorge Chahla ${ }^{2}$ Jack Farr II ${ }^{3}$. Robert F. LaPrade ${ }^{4}$. Elizabeth A. Arendt ${ }^{5}$. Vicente Sanchis-Alfonso ${ }^{6}$. \\ William R. Post ${ }^{7}$. John P. Fulkerson ${ }^{8,9}$
}

Published online: 23 November 2018

(c) European Society of Sports Traumatology, Knee Surgery, Arthroscopy (ESSKA) 2018

\section{Correction to: \\ Knee Surgery, Sports Traumatology, Arthroscopy \\ https://doi.org/10.1007/s00167-018-5266-y}

Unfortunately, the middle name of author was incorrectly published as Jorge A. Chahla instead of Jorge Chahla in the original article. The author name is now corrected here by this correction paper. Original article has been corrected.

The original article can be found online at https://doi.org/10.1007/ s00167-018-5266-y.

Miho J. Tanaka

Mtanaka4@jhmi.edu

Jorge Chahla

jachahla@msn.com

Jack Farr II

jfarr@orthoindy.com

Robert F. LaPrade

rlaprade@thesteadmanclinic.com

Elizabeth A. Arendt

arend001@umn.edu

Vicente Sanchis-Alfonso

vicente.sanchis.alfonso@gmail.com

William R. Post

wpost@wvortho.com

John P. Fulkerson

patelladoc@aol.com

1 Department of Orthopaedic Surgery, Johns Hopkins

University School of Medicine, 601 N. Caroline St., Suite

5250, 21287 Baltimore, MD, USA
2 Cedars-Sinai Kerlan Jobe Institute, Santa Monica, CA, USA

3 OrthoIndy Knee Preservation and Cartilage Restoration Center, Orthopedic Surgery, Indiana University School of Medicine, Indianapolis, IN, USA

4 The Steadman Clinic, Vail, CO, USA

5 Department of Orthopaedic Surgery, University of Minnesota, Minneapolis, MN, USA

6 Department of Orthopaedic Surgery, Hospital Arnau de Vilanova, Valencia, Spain

7 Mountaineer Orthopedic Specialists, LLC, Morgantown, WV, USA

8 Orthopedic Associates of Hartford, Farmington, CT, USA

9 Department of Orthopedic Surgery, University of Connecticut School of Medicine, Farmington, CT, USA 